\title{
Curcumin Modulates DNA Methyltransferase Functions in a Cellular Model of Diabetic Retinopathy
}

\author{
Andrea Maugeri, ${ }^{1}$ Maria Grazia Mazzone, ${ }^{2}$ Francesco Giuliano, ${ }^{2}$ Manlio Vinciguerra $\left(\mathbb{D},{ }^{3}\right.$ \\ Guido Basile, ${ }^{4}$ Martina Barchitta $\left(\mathbb{D},{ }^{1}\right.$ and Antonella Agodi ${ }^{1}{ }^{1}$ \\ ${ }^{1}$ Department of Medical and Surgical Sciences and Advanced Technologies "GF Ingrassia”, University of Catania, Via S. Sofia 87, \\ Catania 95123, Italy \\ ${ }^{2}$ Research and Development Department, SIFI SpA, Via Ercole Patti 36, Catania 95025, Italy \\ ${ }^{3}$ International Clinical Research Center, St. Anne's University Hospital, Brno, Czech Republic \\ ${ }^{4}$ Department of General Surgery and Medical-Surgical Specialties, University of Catania, Via Plebiscito 628, Catania 95124, Italy
}

Correspondence should be addressed to Manlio Vinciguerra; manlio.vinciguerra@fnusa.cz and Antonella Agodi; agodia@unict.it Received 2 April 2018; Accepted 5 June 2018; Published 2 July 2018

Academic Editor: Ewa Stachowska

Copyright (C) 2018 Andrea Maugeri et al. This is an open access article distributed under the Creative Commons Attribution License, which permits unrestricted use, distribution, and reproduction in any medium, provided the original work is properly cited.

\begin{abstract}
Hyperglycaemia-induced oxidative stress appears to be involved in the aetiology of diabetic retinopathy (DR), a major public health issue, via altering DNA methylation process. We investigated the effect of hyperglycaemia on retinal DNA methyltransferase (DNMT) expression in diabetic mice, using Gene Expression Omnibus datasets. We also evaluated the effect of curcumin both on high glucose-induced reactive oxygen species (ROS) production and altered DNMT functions, in a cellular model of DR. We observed that three months of hyperglycaemia, in insulin-deficient Ins $2^{\text {Akita }}$ mice, decrease DNMT1 and DNMT3a expression levels. In retinal pigment epithelium (RPE) cells, we also demonstrated that high glucose-induced ROS production precedes upregulation of DNMT expression and activity, suggesting that changes in DNMT function could be mediated by oxidative stress via a potential dual effect. The early effect results in decreased DNMT activity, accompanied by the highest ROS production, while long-term oxidative stress increases DNMT activity and DNMT1 expression. Interestingly, treatment with $25 \mu \mathrm{M}$ curcumin for 6 hours restores ROS production, as well as DNMT functions, altered by the exposure of RPE to acute and chronic high glucose concentration. Our study suggests that curcumin may represent an effective antioxidant compound against $\mathrm{DR}$, via restoring oxidative stress and DNMT functions, though further studies are recommended.
\end{abstract}

\section{Introduction}

The growing incidence of diabetes and longer life span in the aging population point towards an increase in patients with diabetic retinopathy (DR), a diabetes-related microvascular complication which represents a major public health issue as one of the leading causes of blindness in elderly adults [1]. Clinically, DR can be classified into nonproliferative and proliferative: the first is characterized by macular oedema, while the second one may manifest as proliferative retinal neovascularization [2]. The incidence of DR appears to be higher in patients suffering from type 1 than in those with type 2 diabetes [3]. However, regardless of the type of diabetes, both hyperglycaemia and hyperglycaemia-induced oxidative stress have been identified as the major contributing factors $[4,5]$. Moreover, it has been demonstrated that DR progression continues even if normal glycaemic control is restored, suggesting that the harmful effect depends on both the duration and the severity of hyperglycaemic insult [6]. Oxidative stress has been shown to alter histone modifications and DNA methylation [7], which have been further recognized as potential epigenetic mechanisms involved in the pathophysiology of DR [8-11]. The methylation process of DNA is carried out by DNA methyltransferases (DNMTs), a family comprising 5 members, of which only DNMT1, DNMT3a, and DNMT3b are catalytically active. DNMT1 is 
described as the maintenance methyltransferase, while DNMT3A and DNMT3B are de novo methyltransferases [12]. In mammals, methylation almost exclusively occurs at short DNA sequences, termed CpG islands, which typically contain around 5-10 CpGs per $100 \mathrm{bp}$, and up to $80 \%$ of $\mathrm{CpG}$ islands is localized in noncoding regions that mainly contribute to the global methylation status [12]. There are different types of repetitive sequences scattered throughout the genome (e.g., satellite repeat, short interspersed nuclear element, and long interspersed nuclear element-1 (LINE-1)). LINE-1 sequences, accounting for $\approx 18 \%$ of human genome, are widely used as a surrogate marker of global DNA methylation [13-16].

The effects of curcumin, a natural phenol from the rhizome of Curcuma longa, have been determined in animal models and in vitro systems [17]. Recent literature reports the wound healing properties of curcumin indicating the capability to accelerate the wound healing process [18]. Particularly, the anti-inflammatory and antioxidant potentials of curcumin enhance the healing process quite effectively in diabetic rats [19]. Several lines of evidence have shown that curcumin significantly decreases lipid peroxidation, increases intracellular antioxidant amount, regulates antioxidant enzymes, and scavenges hyperglycaemia-induced ROS production [20, 21]. Particularly, treatment with curcumin reduced ROS production both in retinal pigment epithelium (RPE) cells [22] and in the retina of diabetic rats [23]. However, the relying antioxidant activity of curcumin on epigenetic mechanisms has not been completely elucidated.

The present study investigated the effect of hyperglycaemia and high glucose-induced oxidative stress on retinal DNMT activity and expression, as well as on LINE-1 methylation levels. To achieve this objective, we compared the expression levels of DNMTs in the retina of diabetic and nondiabetic mice, using the Gene Expression Omnibus (GEO) datasets. In RPE cells, we analysed the time-related effect of high glucose condition on ROS production and DNMT activity and expression. Finally, we evaluated whether the antioxidant properties of curcumin may restore high glucose-induced changes of DNMT function in RPE cells.

\section{Materials and Methods}

2.1. Microarray Data. Microarray datasets were retrieved and downloaded from the Gene Expression Omnibus (GEO) database (http://www.ncbi.nlm.nih.gov/geo) of the National Center for Biotechnology Information (NCBI), using the keyword "diabetic retinopathy." The GSE12610 dataset included expression microarray profiling data derived from the whole retina of adult CD1 streptozotocin- (STZ-) induced diabetic mice (3-week and 5-week) and age-matched controls. Mice with glucose levels above $250 \mathrm{mg} / \mathrm{dL}$ were considered diabetic from the date of the last injection. To get adequate amounts of RNA, four retinas (2 animals) for each group were pooled. Total RNA was extracted and processed for being hybridized on the GPL1261 platform of Affymetrix Mouse Genome 4302.0 Array (Affymetrix Inc., Santa Clara, CA, USA). The
GSE19122 dataset compared expression microarray profiling data derived from the whole retina of eight C57BL/6J STZinduced diabetic mice and nine insulin-deficient Ins $2^{\text {Akita }}$ mice after 3 months of hyperglycaemia, with those derived from eight controls. Total RNA was extracted and processed for being hybridized on the GPL6885 platform of Illumina MouseRef-8 v2.0 expression Beadchip (Illumina Inc., San Diego, USA) [24]. The dataset GSE55389 included expression microarray profiling data derived from the whole retina of four 8-week-old $\mathrm{db} / \mathrm{db}$ diabetic mice and four agematched lean nondiabetic controls. Total RNA was extracted and processed for being hybridized on the GPL6246 platform of Affymetrix Mouse Gene 1.0 ST Array (Affymetrix Inc., Santa Clara, CA, USA) [25]. Due to skewed distribution, for each dataset, raw data of DNMT1, DNMT3a, and DNMT3b were extracted and signal values from the selected genes were log-transformed and normalized using the $\mathrm{MeV}$ free software online. The difference in log-transformed DNMT expression levels between diabetic mice and controls was compared using Student's $t$-test and reported as the absolute mean difference (MD).

2.2. Cell Culture. The human retinal pigment epithelial cells (ARPE-19) were purchased from the American Type Culture Collection (Manassas, VA) and maintained in Dulbecco's Modified Eagle's medium (DMEM) supplemented with $10 \%$ foetal bovine serum (FBS; Gibco BRL), $100 \mathrm{U} / \mathrm{mL}$ of penicillin and $100 \mathrm{lg} / \mathrm{mL}$ of streptomycin (Gibco BRL). Cells maintained at the following glucose conditions were used:

(i) Cells maintained at $5.5 \mathrm{mM}$ glucose for 3 weeks (normal glucose (NG) condition)

(ii) Cells maintained at $25 \mathrm{mM}$ glucose for 3 weeks (chronic high glucose (HG) condition)

(iii) Cells maintained at $5.5 \mathrm{mM}$ glucose for 3 weeks and then transferred to $25 \mathrm{mM}$ glucose medium for 24 hours (Acute HG condition)

Normal glucose condition $(5.5 \mathrm{mM})$ corresponded to the fasting plasma glucose level of diabetes-free subjects, while high glucose condition $(25 \mathrm{mM})$ reflected $2 \mathrm{~h}$ after-meal plasma glucose level in diabetic patients [26-28]. To rule out the potential effect of hyperosmotic stress, cells maintained in $25 \mathrm{mM}$ mannitol medium were used as osmotic control. Cells between 6 and 10 passages were used in all experiments and incubated at $37^{\circ} \mathrm{C}$ and $5 \% \mathrm{CO} 2$. The medium was changed every 48 hours. A flow-chart of in vitro experiments was reported in Figure S1.

2.3. Curcumin Treatment. The effect of curcumin on ROS production, DNMT activity and expression, and LINE-1 methylation was evaluated in ARPE-19 cells. In brief, cells were maintained either at $5.5 \mathrm{mM}$ or at $25 \mathrm{mM}$ glucose concentrations or maintained at $5.5 \mathrm{mM}$ glucose and then transferred to $25 \mathrm{mM}$ glucose medium. After 24 hours, cells were exposed to $25 \mu \mathrm{M}$ curcumin (Sigma Aldrich, St. Louis, MO) for 6 hours, and then processed to further analyses. 
2.4. Determination of Cell Viability. To evaluate the effect of curcumin on cell viability, the Thiazolyl blue tetrazolium bromide (MTT) assay was performed. Cells, maintained either in normal or in high glucose conditions, were seeded at a density of $2.0 \times 10^{4}$ cells/well in a 96-well plate. Cells were then exposed to increasing concentrations $(1-50 \mu \mathrm{M})$ of curcumin for $6 \mathrm{~h}$. To determine the time-dependent effect of curcumin treatment on cell viability, cells were also exposed to $25 \mu \mathrm{M}$ curcumin for 1 to 24 hours. MTT $(1.6 \mathrm{mg} / \mathrm{mL})$ was added to the cells in each well, followed by a further incubation at $37^{\circ} \mathrm{C}$ for $4 \mathrm{~h}$. After removing the solution, cells were resuspended in $100 \mu \mathrm{L}$ of dimethyl sulfoxide (DMSO). The optical density was read at $540 \mathrm{~nm}$, and the background was subtracted at $670 \mathrm{~nm}$. Cell viability (\%) was reported as (OD of the treated samples/OD of the control) $\times 100$.

2.5. Determination of Reactive Oxygen Species (ROS). The intracellular ROS level was determined using the Abcam cellular ROS detection assay kit (Abcam plc, Cambridge, UK). The redox-sensitive fluoroprobe $2^{\prime}, 7^{\prime}$-dichlorofluorescin diacetate (DCFDA) is a fluorogenic dye that measures hydroxyl, peroxyl, and other reactive oxygen species (ROS) activity within the cell. After diffusion into the cell, DCFDA is deacetylated by cellular esterases to a nonfluorescent compound, which is later oxidized by ROS into $2^{\prime}, 7^{\prime}$-dichlorofluorescein (DCF). DCF is a highly fluorescent compound which can be detected by fluorescence spectroscopy with maximum excitation and emission spectra of $495 \mathrm{~nm}$ and $529 \mathrm{~nm}$, respectively. Briefly, ARPE-19 cells were seeded at a density of $2.0 \times 10^{4}$ cells/well in a dark, clear bottom 96-well microplate. After removing the media, cells were rinsed with $100 \mu \mathrm{L} /$ well of $1 \mathrm{x}$ buffer and stained by adding $100 \mu \mathrm{L} /$ well of DCFDA solution. Cells were incubated with DCFDA solution for 45 minutes at $37^{\circ} \mathrm{C}$ in the dark. After removing DCFDA solution, $100 \mu \mathrm{L} /$ well of $1 \mathrm{x}$ buffer was added and fluorescence was immediately measured $(\mathrm{Ex} / \mathrm{Em}=485 / 535 \mathrm{~nm})$.

2.6. Nuclear Protein Extraction. Nuclear proteins were extracted from ARPE-19 cells using the Nuclear Extraction Kit (Abcam plc, Cambridge, UK). In brief, cells were grown to $70-80 \%$ confluency and removed by trypsinization following standard protocols. Cell pellets $\left(2 \times 10^{6}\right.$ cells) were resuspended in $200 \mu \mathrm{L}$ of preextraction buffer and incubated on ice for 10 minutes. After centrifugation, nuclear pellet was resuspended in $400 \mu \mathrm{L}$ of extraction buffer and incubated on ice for 15 minutes, with vortexing every 3 minutes. Finally, the suspension was centrifuged for 10 minutes at $14,000 \mathrm{rpm}$ at $4^{\circ} \mathrm{C}$; the supernatant was transferred into a new microcentrifuge vial to measure the protein concentration of the nuclear extract. Nuclear protein quantification was performed by the Qubit fluorometer (Invitrogen) using the Qubit Protein Assay Kit.

2.7. DNMT Activity Quantification. Quantification of DNMT activity was performed using the colorimetric DNMT Activity Quantification Kit (Abcam plc, Cambridge, UK), suitable for measuring total DNMT activity according to the manufacturer's instructions. In brief, $7.5 \mathrm{ng}$ of nuclear extracts was diluted in $50 \mu \mathrm{L} /$ well of reaction solution. The 96-well plate, including blank and positive control, was covered and incubated at $37^{\circ} \mathrm{C}$ for $120 \mathrm{~min}$. After removing the reaction solution, each well was washed with $150 \mu \mathrm{L}$ of wash buffer for three times, and $50 \mu \mathrm{L} /$ well of the diluted capture antibody was added. The plate was covered with an aluminium foil and incubated at room temperature for $60 \mathrm{~min}$. After removing the capture antibody, each well was rinsed with $150 \mu \mathrm{L}$ of the wash buffer for three times, and $50 \mu \mathrm{L} /$ well of the diluted detection antibody was added. The plate was covered with an aluminium foil and incubated at room temperature for $30 \mathrm{~min}$. After the detection antibody was removed, each well was rinsed with $150 \mu \mathrm{L}$ of the wash buffer for four times, and $50 \mu \mathrm{L} /$ well of the enhancer solution was added. The plate was covered with an aluminium foil and incubated at room temperature for $30 \mathrm{~min}$. After removing the enhancer solution, each well was rinsed with $150 \mu \mathrm{L}$ of the wash buffer for five times, and $100 \mu \mathrm{L} /$ well of the developer solution was added. The plate was covered with an aluminium foil and incubated at room temperature for $10 \mathrm{~min}$, away from direct light. When the positive control turned to medium blue, $100 \mu \mathrm{L} /$ well of stop solution was added to stop enzyme reaction. Absorbance was read on a microplate reader within 2 to $10 \mathrm{~min}$ at $450 \mathrm{~nm}$ with an optional reference wavelength of $655 \mathrm{~nm}$. DNMT activity was reported as the percentage of control.

2.8. Quantitative Real-Time Polymerase Chain Reaction $(q P C R)$. Total cellular RNA was extracted using Trizol $^{\circledR}$ Reagent (Invitrogen, Carlsbad, CA, USA), and RNA was reverse transcribed to single-stranded cDNA using the SuperScript III Reverse Transcriptase (Applied Biosystems, Foster City, CA, USA) according to the manufacturer's protocols. mRNA levels were determined by qPCR with TaqMan Gene Expression Assays (Life Technologies, Monza, MB) using the 7300 Real-Time PCR System (Applied Biosystems, Foster City, CA, USA). Specific primers were used to detect DNMT1 (assay number Hs00945875_m1), DNMT3a (Hs01027162_m1), and DNMT3b (Hs00171876_m1). Threshold cycle values in each sample were used to calculate the number of cell equivalents in the test samples. The data were normalized to the values for GAPDH expression (Hs02758991_g1).

2.9. LINE-1 Methylation Analysis. DNA was extracted using the DNeasy Blood and Tissue kit and quantified using the Qubit dsDNA HS (High Sensitivity) Assay Kit according to the manufacturer's protocols. The methylation analysis of the LINE-1 promoter (GeneBank accession number $\mathrm{X} 58075)$ was investigated by pyrosequencing-based methylation analysis, using the PyroMark Q24 instrument (Qiagen), after DNA bisulfite conversion. Bisulfite treatment of $20 \mu \mathrm{g}$ of DNA extracted from each sample was completed using the Epitect Bisulfite kit (Qiagen), and the converted DNA was eluted with $20 \mu \mathrm{L}$ elution buffer. The bisulfitemodified DNA was stored at $-80^{\circ} \mathrm{C}$ until used.

A reaction volume of $25 \mathrm{~mL}$ was amplified by polymerase chain reaction (PCR), using the PyroMark PCR Kit (Qiagen). 
According to the manufacturer's instructions, each reaction mixture contained $1.5 \mu \mathrm{L}$ of bisulfite-converted DNA, $12.5 \mu \mathrm{L}$ of PyroMark PCR Master Mix 2X, containing HotStart Taq DNA Polymerase, $2.5 \mu \mathrm{L}$ of CoralLoad Concentrate $10 \mathrm{X}$, and $2 \mu \mathrm{L}$ of the forward primer $\left(5^{\prime}\right.$-TTTTGAGTTAG GTGTGGGATATA- $3^{\prime}$ ) and the reverse-biotinylated primer $\left(5^{\prime}\right.$-biotin-AAAATCAAAAAATTCCCTTTC- $\left.3^{\prime}\right) \quad(0.2 \mu \mathrm{M}$ for each) $[29,30]$. HotStart PCR cycling conditions were 1 cycle at $95^{\circ} \mathrm{C}$ for $15 \mathrm{~min} ; 40$ cycles at $94^{\circ} \mathrm{C}$ for $30 \mathrm{~s}$, $50^{\circ} \mathrm{C}$ for $30 \mathrm{~s}$, and $72^{\circ} \mathrm{C}$ for $30 \mathrm{~s}$; and a final extension at $72^{\circ} \mathrm{C}$ for $10 \mathrm{~min}$. Electrophoresis of the PCR products was performed on a $2 \%$ Seakem Agarose (Lonza, ME, USA). Gels were stained with GelRed (Biotium Inc., Hayward, CA, USA) in order to visualize the amplified DNA fragment of $290 \mathrm{bps}$.

The biotinylated PCR product was purified and made single stranded to act as a template using the Pyrosequencing Vacuum Prep Tool (Biotage Inc., Charlottesville, VA, USA). The biotinylated single-stranded product was annealed to the pyrosequencing primer ( 5 ' AGTTAGGTGTGGGATATAG $\left.\mathrm{T}-3^{\prime}\right)$ and then subjected to sequencing using an automatically generated nucleotide dispensation order for sequences to be analysed corresponding to each reaction. The pyrograms were analysed using allele quantification mode to determine the proportion of cytosine/thymine and, hence, methylated and unmethylated cytosines at the targeted position(s). The degree of methylation was evaluated at three specific cytosine followed by guanine (CpG) methylation sites, as well as the average percent methylation of the three CpG sites.

2.10. Statistical Analysis. All experiments were performed in triplicate for three times. Results were reported as the MD or the fold change of control. Differences were assessed by one-way-repeated measure analysis of variance (ANOVA), followed by the Bonferroni post hoc test for multiple comparisons or by Student's $t$-test for comparison of two groups. All the analyses were conducted using GraphPad version 6.0 with a significance level of 0.05 .

\section{Results}

3.1. Analysis of DNMT Expression Using GEO Datasets. Differences in the expression levels of DNMT1, DNMT3a, and DNMT3b, between diabetic mice and controls at different time points, were evaluated in three distinct GEO datasets. Since DR incidence is higher in type 1 diabetes patients [3], we firstly analysed microarray data of type 1 diabetes mouse models. No significant difference was revealed by analysing the GSE12610 dataset, which compared adult CD1 STZ-induced diabetic mice, after 3 weeks and 5 weeks from induction, to nondiabetic mice (Figure 1(a)). The GSE19122 dataset reported microarray data of two type I diabetes mouse models, after 3 months of hyperglycaemia, and nondiabetic controls. Data analysis revealed that insulin-deficient Ins $2^{\text {Akita }}$ mice, but not STZ-induced diabetic mice, showed lower DNMT1 $(\mathrm{MD}=-0.28, p<0.001)$ and DNMT3a $(\mathrm{MD}=-0.31, p<0.001)$ expression levels compared to nondiabetic controls (Figures 1(b) and 1c). We also analysed the GSE55389 dataset, which compared 8 -week-old $\mathrm{db} / \mathrm{db}$ type 2 diabetic mice to nondiabetic controls. However, no significant difference in the expression levels of DNMT1, DNMT3a, and DNMT3b was reported (Figure $1(\mathrm{~d})$ ).

3.2. High Glucose-Induced Oxidative Stress Precedes Upregulation of DNMT Expression/Activity in RPE Cells. One of the common features of both type 1 and 2 diabetes is hyperglycaemia-induced oxidative stress in the retina $[4,5]$. Hence, we evaluated the time-dependent effect of high glucose on ROS production in ARPE-19 cells, seeded in 6well plates and maintained either in normal $(5.5 \mathrm{mM})$ or in high glucose $(25 \mathrm{mM})$ condition for 5 days. Under normal glucose condition, ROS production remained stable with increasing values after 96 hours, probably due to cell confluency. Under high glucose condition, ROS production immediately increased after 2 hours, maintaining stable high levels from 2 to 24 hours and then slightly decreased. At each time point, ROS production was higher in cells maintained at high glucose compared to normal glucose condition (Figure 2(a)).

Since the analysis of GEO datasets suggested a possible time-related effect of hyperglycaemia on DNMT expression levels, we performed a time-course analysis of DNMT activity and expression in ARPE-19 cells maintained either in normal or in high glucose condition for 5 days. DNMT activity remained stable under normal glucose condition, whereas it showed a negative peak at 24 hours and a positive peak at 120 hours under high glucose condition (Figure 2(b)). Particularly, significant differences between normal and high glucose conditions were revealed after $24(\mathrm{MD}=-35.44, p<0.05)$ and 120 hours $(\mathrm{MD}=61.93$, $p<0.001)$. This result was partially confirmed by timecourse analysis of DNMT1 expression (Figure 2(c)). After 48 hours, DNMT1 expression level increased in cells under high glucose condition ( $\mathrm{FC}=1.25$ at 72 hours, $\mathrm{FC}=2.21$ at 96 hours, and $\mathrm{FC}=2.33$ at 120 hours) but not in those under normal glucose condition. No significant difference and time-related effect were reported for DNMT3a and DNMT3b expression levels (data not shown). Overall, results from time-course analysis demonstrated that high glucose-induced oxidative stress precedes the upregulation of DNMT expression and activity, suggesting that high glucose-induced changes in DNMT function could be mediated by oxidative stress.

3.3. Effect of Curcumin on Viability and ROS Production in $R P E$ Cells. Consistently with previous studies [20-22], we aimed to evaluate the antioxidant effect of curcumin on high glucose-induced oxidative stress in RPE cells. Firstly, we determined cytotoxicity of curcumin in ARPE-19 cells, grown in a 96-well plate and then exposed to various concentrations of curcumin $(1-50 \mu \mathrm{M})$ for 6 hours or to $25 \mu \mathrm{M}$ curcumin for various durations of exposure. No significant cytotoxic effect was observed with 1-25 $\mu \mathrm{M}$ curcumin, while treatment with $50 \mu \mathrm{M}$ curcumin for $6 \mathrm{~h}$ resulted in $39 \%$ decrease in cell viability $(p<0.01$ ) (Figure $3(\mathrm{a})$ ). Moreover, 


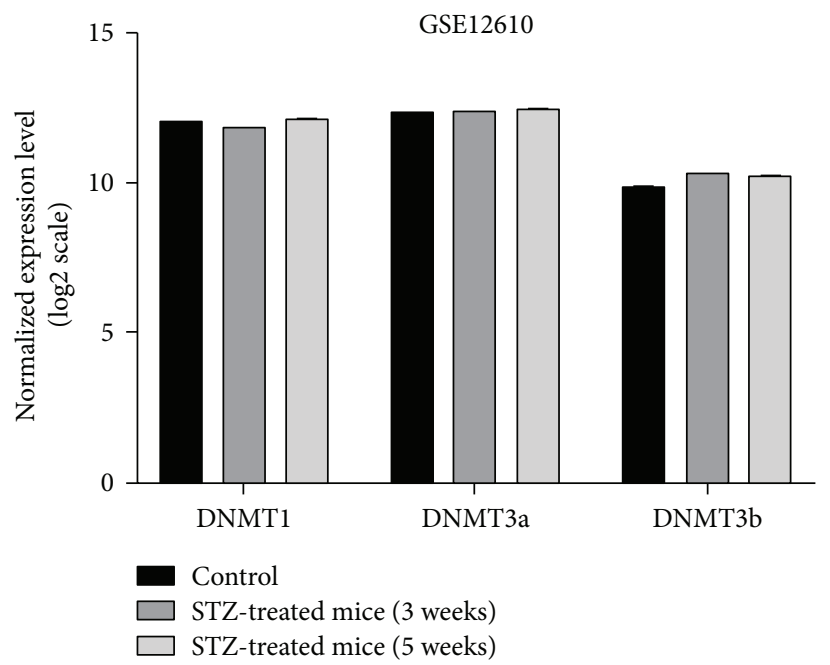

(a)

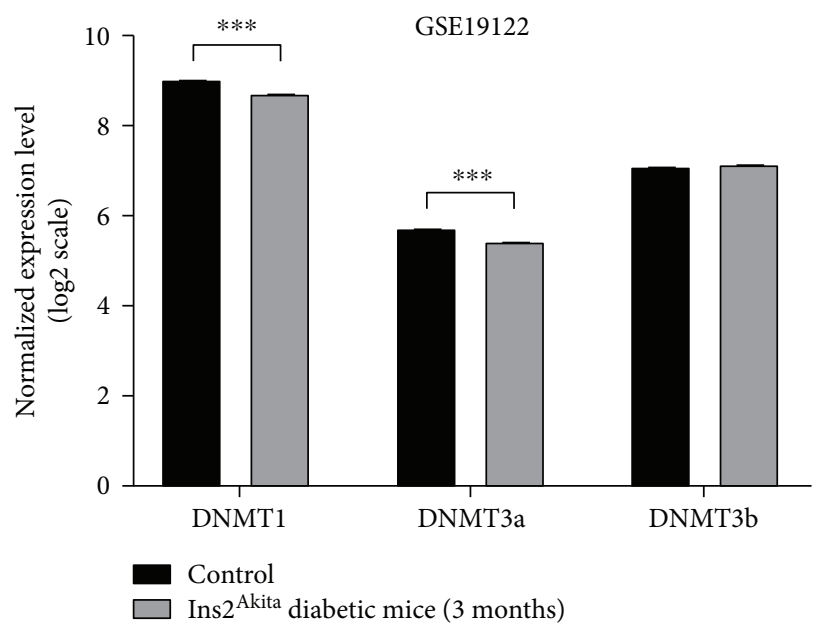

(c)

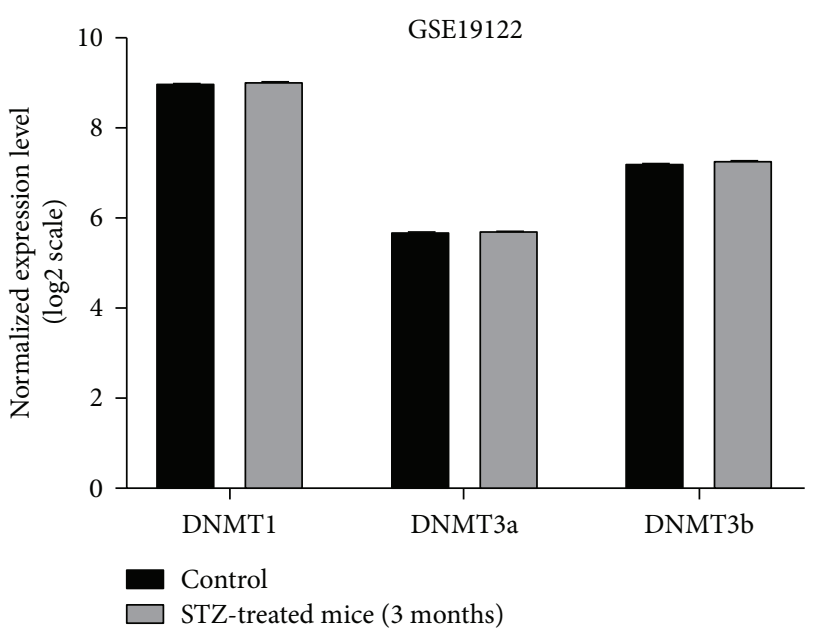

(b)

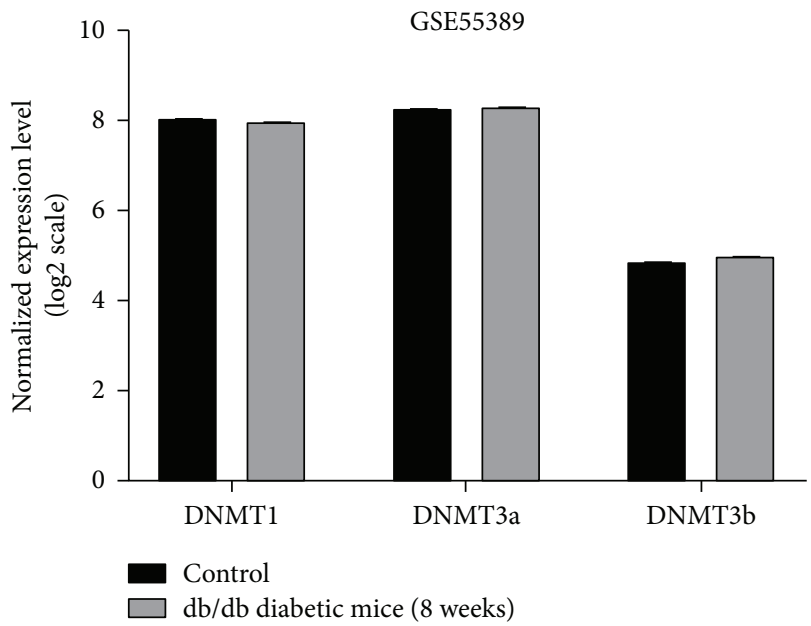

(d)

FIGURE 1: Comparison of DNMT expression using GEO datasets of microarray profiling in mouse models of diabetic retinopathy. (a) Comparison of retinal DNMT expression between adult CD1 streptozotocin- (STZ-) induced diabetic mice (3-week and 5-week) and agematched controls (4 retinas for each group were pooled) using the GSE12610 dataset. (b) Comparison of retinal DNMT expression between eight C57BL/6J STZ-induced diabetic mice, after 3 months of hyperglycaemia, and eight controls, using the GSE19122 dataset. (c) Comparison of retinal DNMT expression between nine insulin-deficient Ins2 ${ }^{\text {Akita }}$ mice, after 3 months of hyperglycaemia, and eight controls, using the GSE19122 dataset. (d) Comparison of retinal DNMT expression between four 8-week-old db/db diabetic mice and four age-matched lean nondiabetic controls, using the GSE55389 dataset. ${ }^{* *} p<0.001$.

treatment with $25 \mu \mathrm{M}$ curcumin for up to 12 hours had no significant effect on cell viability. However, cell viability was reduced by $22 \%(p=0.179)$ and $36 \%(p<0.01)$ of the untreated controls after $25 \mu \mathrm{M}$ exposure for 12 and $24 \mathrm{~h}$, respectively (Figure 3(b)). To avoid potential cytotoxicity, treatment with $25 \mu \mathrm{M}$ curcumin for 6 hours was chosen for further experiments. The effect of curcumin on ROS production was evaluated in ARPE-19 cells maintained at normal glucose or exposed to acute and chronic high glucose condition. Similar to time-course analysis, exposure to acute and chronic high glucose condition increased the intracellular ROS levels compared to normal glucose $(p<0.05$ and $p<0.01$, resp.). However, ROS production was restored by treatment with $25 \mu \mathrm{M}$ curcumin for 6 hours in both cells under acute and chronic high glucose condition (Figure 4(a)).

\subsection{Curcumin Restores Basal Levels of DNMT Activity and} Expression in RPE Cells upon Hyperglycaemic Conditions. We also evaluated the effect of curcumin on DNMT activity and expression. Compared to cells at normal glucose concentration, we confirmed a $35 \%$ decrease in DNMT activity under acute high glucose condition $(p<0.05)$; in contrast, chronic high glucose exposure led to $70 \%$ increase in DNMT activity. However, DNMT activity was restored by treatment with $25 \mu \mathrm{M}$ curcumin for 6 hours in both conditions (Figure 4(b)). With regard to DNMT1 expression level, chronic high glucose exposure up- 


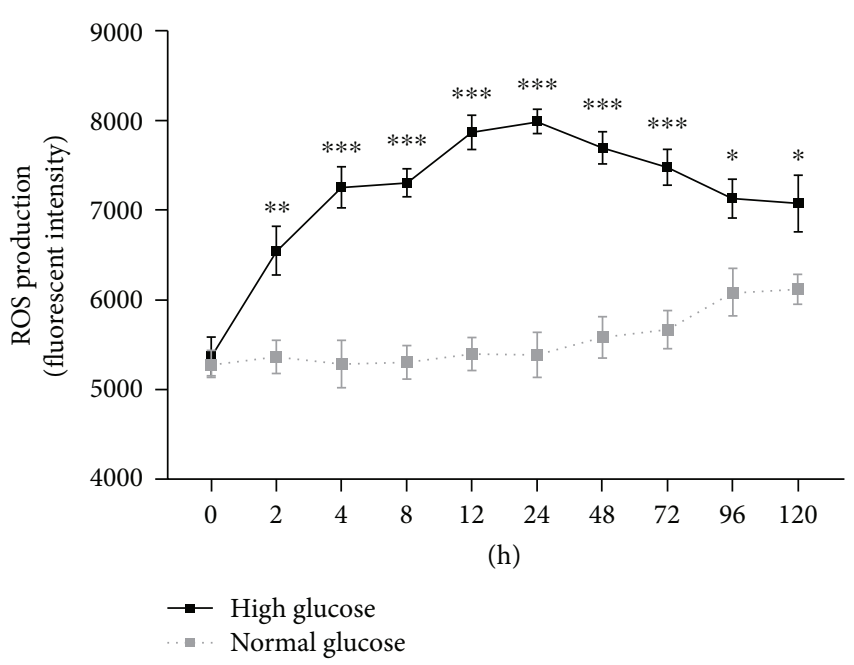

(a)

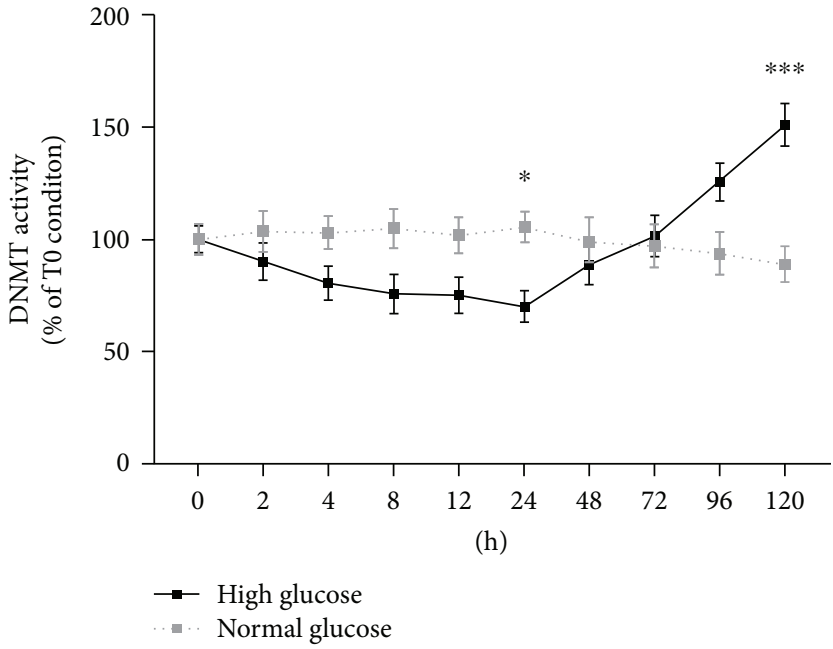

(b)

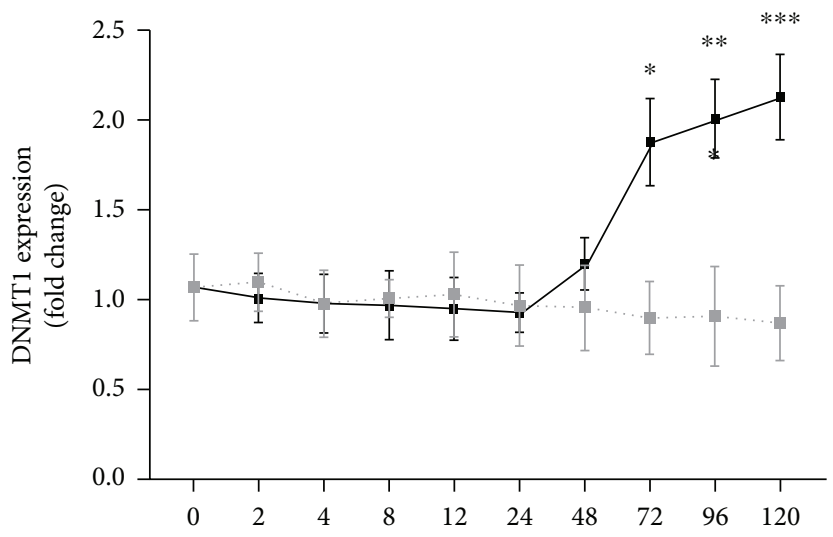

(h)

- High glucose

-.. Normal glucose

(c)

FIGURE 2: Time-dependent effects of high glucose in ARPE-19 cells. (a) Time-course analysis of ROS production in ARPE-19 cells maintained under normal and high glucose conditions. (b) Time-course analysis of total DNMT activity in ARPE-19 cells maintained under normal and high glucose conditions. (c) Time-course analysis of DNMT1 expression in ARPE-19 cells maintained under normal and high glucose conditions. ${ }^{*} p<0.05 ;{ }^{* *} p<0.01 ;{ }^{* * *} p<0.001$

regulated mRNA expression levels compared to cells at normal glucose concentration $(\mathrm{FC}=2.01 ; p<0.05)$. However, consistent with results on DNMT activity, treatment with $25 \mu \mathrm{M}$ curcumin for 6 hours restored DNMT1 expression level (Figure 4(c)). No significant effect of high glucose and curcumin was reported for DNMT3a and DNMT3b expression levels (Figures 4(d) and 4(e)).

3.5. LINE-1 Methylation Analysis. The effect of high glucose exposure and/or curcumin treatment on LINE-1 methylation, a surrogate marker of global DNA methylation, was evaluated using the bisulfite-converted DNA. Consistent with the higher expression level of the maintenance DNMT1, exposure of ARPE-19 cells to acute or chronic high glucose condition did not affect LINE-1 methylation levels. Similarly, no significant effect of treatment with
$25 \mu \mathrm{M}$ curcumin for 6 hours on LINE-1 methylation levels was reported (Figure 4(f)).

\section{Discussion}

Emerging evidence suggests that pathogenesis of diabetesrelated microvascular complications relies on a complex gene-environment interaction [31]. Epigenetic changes, such as DNA methylation, histone modifications, and miRNA regulation, contribute to the dysregulation of signalling pathways (i.e., oxidative stress, inflammation, apoptosis, and aging), modulating the expression of several key genes in diabetes mellitus [32, 33]. The elucidation of epigenetic changes involved in microvascular complications could improve our knowledge of pathophysiology and therapeutic management of these diseases, an important 


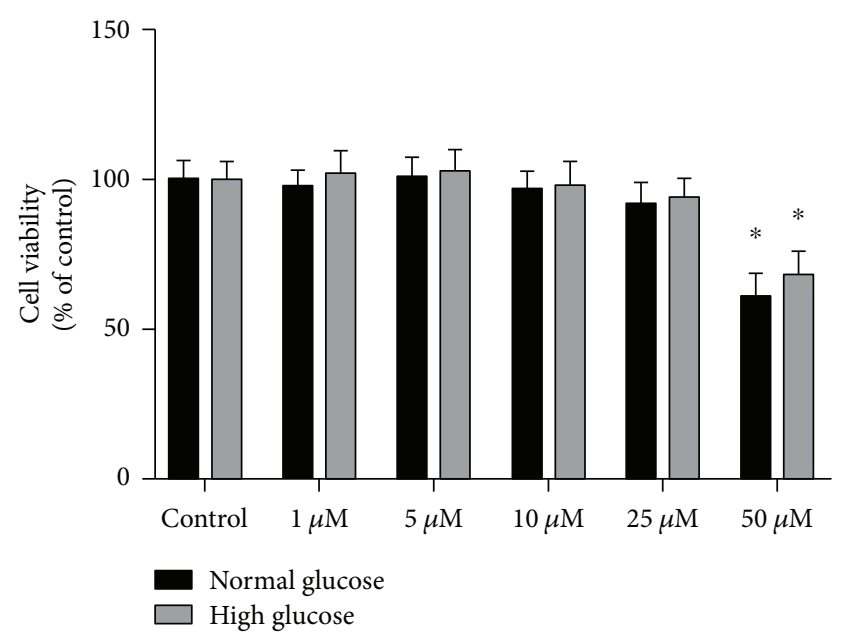

(a)

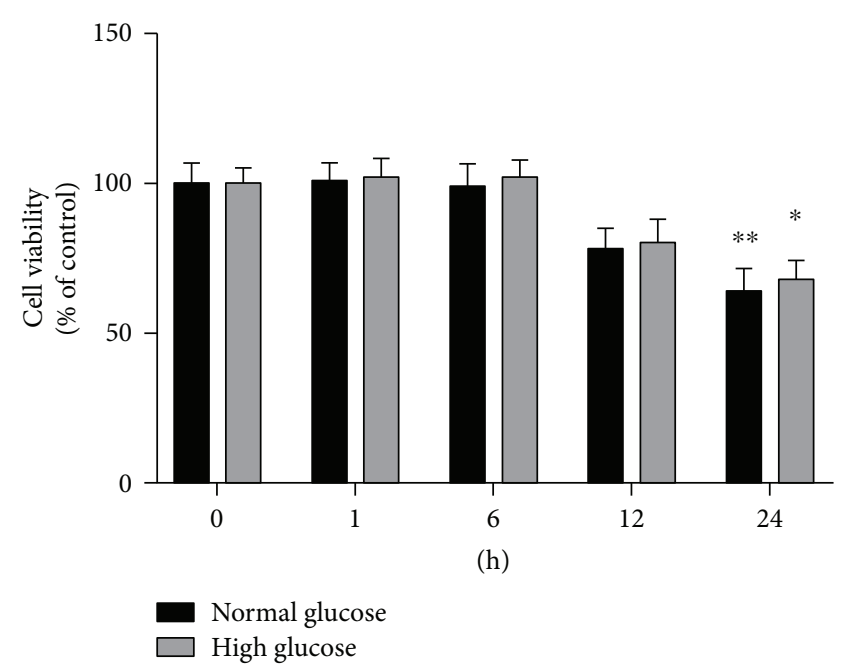

(b)

FIGURE 3: Effect of curcumin on viability of ARPE-19 cells. (a) Thiazolyl blue tetrazolium bromide (MTT) assay performed on ARPE-19 cells, maintained either in normal or in high glucose conditions, and then exposed to increasing concentrations (1-50 $\mu \mathrm{M})$ of curcumin for $6 \mathrm{~h}$. (b) MTT assay performed on ARPE-19 cells, maintained either in normal or in high glucose conditions, and then exposed to $25 \mu \mathrm{M}$ curcumin for 1 to 24 hours. ${ }^{*} p<0.05 ;{ }^{* *} p<0.01$.

public health issue. The role of DNA methylation in vascular complications of diabetes has been recently reviewed [34]. Several lines of evidence described distinct methylation patterns in diabetes-associated cardiovascular complications [35-38], suggesting that high glucose-induced oxidative stress is an important mediator $[39,40]$. Moreover, in vitro and epidemiological studies reported that altered promoter methylation led to the dysregulation of several genes in diabetic nephropathy [41-43].

In diabetic retinopathy, differential DNA methylation of genes involved in the natural killer cell-mediated cytotoxicity pathway was described [44]. Moreover, retinal endothelial cells exposed to high glucose concentration showed increased mitochondrial DNA methylation [8] and an imbalance between methylcytosine and hydroxyl methylation of Matrix metalloproteinase-9 gene [45], impairing mitochondrial integrity and functions. However, in spite of substantial findings suggesting that hyperglycaemia might affect DNA methylation in the retina, the limited knowledge about the effect of high glucose in RPE is needed to be explored.

In this study, we first evaluated whether differences in the retinal DNMT expression levels existed between diabetic and nondiabetic mice, using microarray data of three distinct GEO datasets. Since DR incidence is higher in patients suffering from type 1 diabetes [3], we firstly analysed microarray data of type 1 diabetes mouse models. Data analysis did not reveal dysregulation of DNMT expression levels in 3-week, 5-week, and 3-month STZ-induced diabetic mice. Similarly, inconclusive results have been recognized analysing DNMT expression level of 8-week-old $\mathrm{db} / \mathrm{db}$ diabetic mice, a genetic mouse model of type 2 diabetes. By contrast, three months of hyperglycaemia in insulin-deficient Ins $2^{\text {Akita }}$ mice resulted in the downregulation of DNMT1 and DNMT3a expression. The Ins2 ${ }^{\text {Akita }}$ mouse, harbouring a missense mutation in the Insulin 2 gene, is a model for type 1 diabetes [46].
However, a previous study reported that nonobese Ins2 $2^{\text {Akita }}$ mice also developed type 2 diabetes phenotypes, such as peripheral and hepatic insulin resistance and cardiac remodelling, suggesting long-term intermediate complications between type 1 and type 2 diabetes [47].

Regardless of the type of diabetes, hyperglycaemiainduced oxidative stress in the retina is one of the common features of DR pathogenesis $[4,5]$. When we evaluated the time-dependent effect of high glucose in ARPE-19 cells, ROS production immediately increased after 2 hours of exposure, maintaining stable high levels from 2 to 24 hours, and then slightly decreased. Particularly, at each time point, ROS production was higher in cells maintained at high glucose compared to normal glucose condition.

Previous studies suggested that high glucose-induced oxidative stress might modulate epigenetic changes involved in the pathophysiology of DR $[4,8-11,45,48]$. This substantial evidence, together with findings from GEO dataset analysis, prompted us to determine the effect of high glucose on DNMT function, taking into account the duration of insult. In ARPE-19 cells maintained at different glucose conditions, we demonstrated the time-related effect of high glucose exposure on DNMT activity, as shown by the time-course analysis, with a negative peak after 24 hours and a positive peak after 120 hours. Consistently, the high glucoseinduced effect on DNMT expression was evident after 48 hours from the insult, with the upregulation of DNMT1. By contrast, we did not observe dysregulation of DNMT3a and DNMT3b expression.

Since DNMT1 is responsible for maintenance of DNA methylation on hemimethylated DNA [12], we also evaluated the effect of high glucose exposure on global DNA methylation, using LINE-1 methylation level as a surrogate marker. Consistent with higher DNMT1 expression, we did not observe differences in LINE-1 methylation levels between 


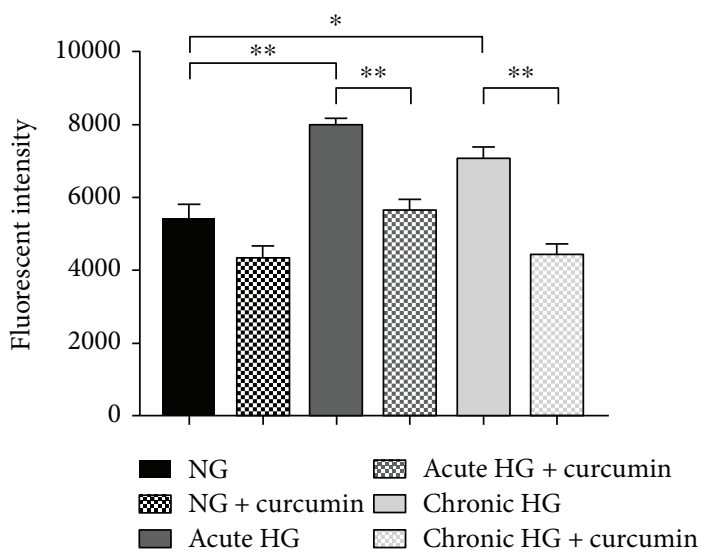

(a)

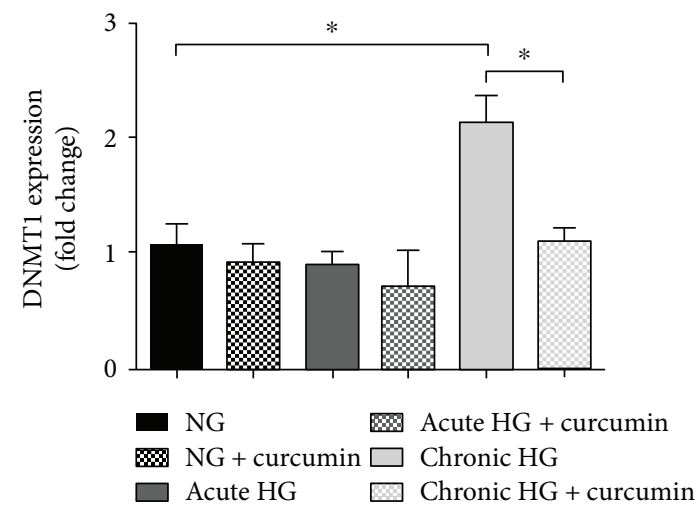

(c)

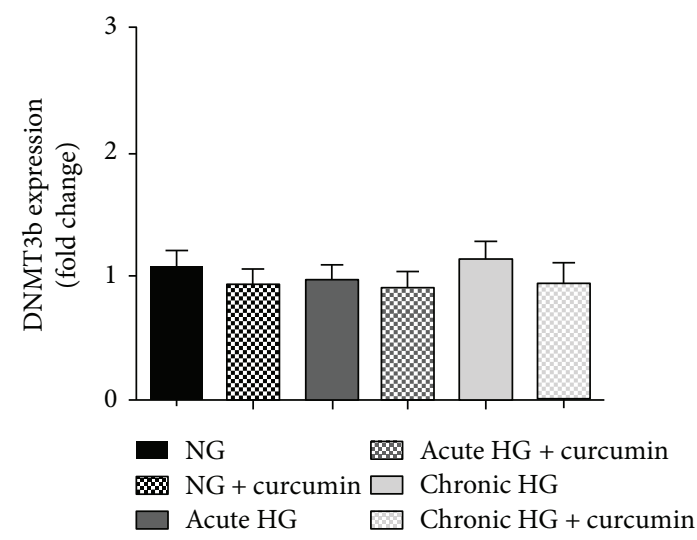

(e)

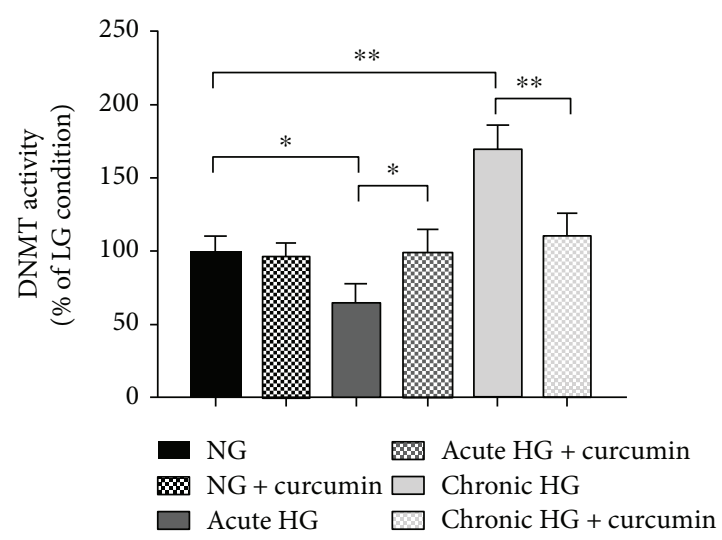

(b)

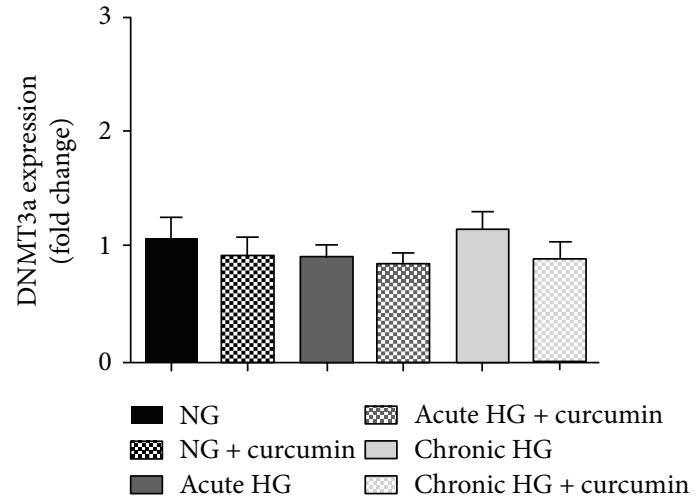

(d)

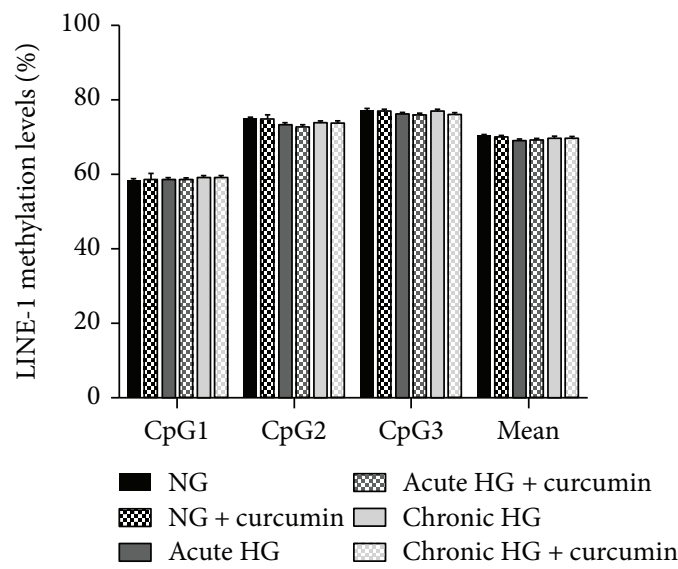

(f)

FIGURE 4: Effects of curcumin on ROS production and DNMT function in ARPE-19 cells. (a) Comparison of ROS production in ARPE-19 cells, maintained either in normal or in high glucose conditions (acute and chronic exposure), and then exposed to $25 \mu \mathrm{M}$ curcumin for 6 hours. (b) Comparison of total DNMT activity in ARPE-19 cells, maintained either in normal or in high glucose conditions (acute and chronic exposure), and then exposed to $25 \mu \mathrm{M}$ curcumin for 6 hours. (c-e) Comparison of DNMT expression in ARPE-19 cells, maintained either in normal or in high glucose conditions (acute and chronic exposure), and then exposed to $25 \mu \mathrm{M}$ curcumin for 6 hours. (f) Comparison of LINE-1 methylation level in ARPE-19 cells, maintained either in normal or in high glucose conditions (acute and chronic exposure), and then exposed to $25 \mu \mathrm{M}$ curcumin for 6 hours. ${ }^{*} p<0.05{ }^{*}{ }^{*} p<0.01$.

cells maintained at normal glucose concentration and those exposed to acute or chronic high glucose condition. However, the potential effects on other repetitive sequences and/or on specific promoter regions cannot be completely excluded.
Our data were in line with previous studies which demonstrated that hyperglycaemia significantly increased both DNMT activity and DNMT1 expression in retinal endothelial cells $[8,45,49]$. These changes persisted even 
when the glucose level is normalized, indicating that DNA methylation is probably involved in the metabolic memory of DR [11, 49-51].

This study, to our knowledge, is the first to demonstrate that high glucose-induced oxidative stress precedes the upregulation of DNMT expression and activity in RPE, suggesting that changes in DNMT function could be mediated by oxidative stress via a potential dual effect. The early effect results in decreasing DNMT activity, accompanied by the highest ROS production, while longterm oxidative stress increases DNMT activity and DNMT1 expression. It is plausible that ROS production is involved in the activation of redox-sensitive enzymes, accelerating the reaction of DNA methylation via deprotonating the cytosine molecule [52]. On the other side, it has also been demonstrated that inhibition of DNMTs, using the DNMT inhibitor RG108 (RG), protected RPE from detrimental effects of oxidative stress by the modulation of antioxidant enzyme gene expression [53]. Although the temporal relationship between high glucose-induced oxidative stress and changes in DNMT function appears evident, further in vitro and in vivo studies, using antioxidants and DNMT inhibitors, are recommended to better clarify molecular pathways involved in this mechanism.

Curcumin is considered, especially for its antioxidant properties, an interesting phytochemical candidate for the treatment of hyper-inflammatory wounds such as chronic diabetic wounds. Since it has been demonstrated that topical curcumin treatment of the wounds of diabetic rats showed enhanced angiogenesis [54], it will be interesting to evaluate the efficacy of topical curcumin on human diabetic wounds [55]. Extensive researches have increase the disease set for which curcumin may be valuable, and the identification of molecular targets will help future research in the development of curcumin as an important therapeutic agent [56]. In the present study, we also investigated whether antioxidant properties of curcumin might restore the high glucose-induced changes in RPE cells. Growing body of evidence demonstrated the pleiotropic effect of curcumin on several signalling pathways, via modulating the expression and activation of cellular regulatory systems, such as $\mathrm{NF} \kappa \mathrm{B}, \mathrm{AKT}$, growth factors, and Nrf2 transcription factor [57-64]. Consistent with previous works $[65,66]$, we observed that treatment with $25 \mu \mathrm{M}$ curcumin for up to 12 hours had no significant effect on cell viability. Interestingly, we demonstrated that curcumin treatment for 6 hours reduced ROS production associated with acute and chronic exposure to high glucose concentration. In turn, the normalization of intracellular ROS levels restored the DNMT activity and DNMT1 expression. These results suggest that the antioxidant properties of curcumin might exert a beneficial effect on high glucose-induced changes in DNMT function. In line with this evidence, a previous work also demonstrated that curcumin downregulated the oxidative stress-induced expression of miR-302, an inhibitor of DNMT1 [65]. However, further studies are needed to explore if curcumin modulates DNMT function via an antioxidant effect or if it reduces oxidative stress acting on DNMT inhibition.
One of the main weaknesses of our study is that it is not evident if curcumin mainly acts as an antioxidant or DNMT inhibitor. Since curcumin treatment restored both ROS production and DNMT functions, further experiments should evaluate whether the effect of curcumin depends on the oxidative and/or DNMT pathways. Moreover, inconclusive evidence from in vivo studies exists. While we did not reveal the dysregulation of DNMT expression using microarray data of short-term type 1 diabetes mouse models, three months of hyperglycaemia in insulin-deficient Ins $2^{\text {Akita }}$ mice resulted in the downregulation of DNMT1 and DNMT3a expression. As reported, the Ins $2^{\text {Akita }}$ mouse is a model for type 1 diabetes, which also developed type 2 diabetes phenotypes. Overall, these findings suggest the long-term intermediate effect of type 1 and type 2 diabetes on DNA methylation, but they also point out the need for additional in vivo studies. Finally, we observed that treatment with $25 \mu \mathrm{M}$ curcumin $(\approx 9.2 \mu \mathrm{g} / \mathrm{mL})$ for up to 12 hours had no significant effect on cell viability, which was consistent with previous in vitro studies $[65,66]$. In addition, a previous clinical trial found that daily high-dose curcumin consumption-up to $3.6 \mathrm{~g}$-was not associated with toxicity and adverse outcomes [67]. However, pharmacokinetic studies of oral Curcuma extracts in rats showed poor absorption, rapid metabolism, and elimination, which in turn suggest a low oral bioavailability $[68,69]$. On the other hand, it is well established that curcumin passes through the blood-brain barrier, and dietary supplementation $(\approx 0.2 \%$ in diet) was found to be effective against retinal degeneration in an in vivo model of light-induced retinal degeneration [70, 71]. Accordingly, further studies should be encouraged to evaluate how much diet-supplemented curcumin reaches the human retina.

\section{Conclusions}

For the first time, we demonstrated that high glucoseinduced ROS production precedes the upregulation of DNMT expression and activity in RPE, suggesting that changes in DNMT function could be mediated by oxidative stress. Curcumin may represent an effective antioxidant compound to restore DNMT expression and function. However, further in vitro and in vivo studies and welldesigned epidemiological studies are recommended to better clarify whether curcumin mainly acts as an antioxidant or a DNMT inhibitor.

\section{Data Availability}

The data used to support the findings of this study are available from the co-corresponding authors upon request.

\section{Conflicts of Interest}

Maria Grazia Mazzone and Francesco Giuliano are employees of SIFI SpA. The other authors declare no conflict of interest. 


\section{Acknowledgments}

Manlio Vinciguerra is supported by the European Social Fund and European Regional Development Fund Project MAGNET (no. CZ.02.1.01/0.0/0.0/15_003/0000492). Andrea Maugeri, Martina Barchitta, and Antonella Agodi are supported by the Department of Medical and Surgical Sciences and Advanced Technologies "GF Ingrassia”, Università di Catania (Piano triennale di sviluppo delle attività di ricerca scientifica del dipartimento-2016-18).

\section{Supplementary Materials}

Figure S1: flow chart of in vitro experiments. (Supplementary Materials)

\section{References}

[1] S. R. Flaxman, R. R. A. Bourne, S. Resnikoff et al., "Global causes of blindness and distance vision impairment 19902020: a systematic review and meta-analysis," The Lancet Global Health, vol. 5, no. 12, pp. e1221-e1234, 2017.

[2] N. Congdon, Y. Zheng, and M. He, "The worldwide epidemic of diabetic retinopathy," Indian Journal of Ophthalmology, vol. 60 , no. 5, pp. 428-431, 2012.

[3] J. W. Yau, S. L. Rogers, R. Kawasaki et al., "Global prevalence and major risk factors of diabetic retinopathy," Diabetes Care, vol. 35, no. 3, pp. 556-564, 2012.

[4] S. A. Madsen-Bouterse and R. A. Kowluru, "Oxidative stress and diabetic retinopathy: pathophysiological mechanisms and treatment perspectives," Reviews in Endocrine \& Metabolic Disorders, vol. 9, no. 4, pp. 315-327, 2008.

[5] J. M. Santos, G. Mohammad, Q. Zhong, and R. A. Kowluru, "Diabetic retinopathy, superoxide damage and antioxidants," Current Pharmaceutical Biotechnology, vol. 12, no. 3, pp. 352-361, 2011.

[6] L. P. Aiello and DCCT/EDIC Research Group, "Diabetic retinopathy and other ocular findings in the diabetes control and complications trial/epidemiology of diabetes interventions and complications study," Diabetes Care, vol. 37, no. 1, pp. 17-23, 2014.

[7] R. A. Kowluru, J. M. Santos, and M. Mishra, "Epigenetic modifications and diabetic retinopathy," BioMed Research International, vol. 2013, Article ID 635284, 9 pages, 2013.

[8] M. Mishra and R. A. Kowluru, "Epigenetic modification of mitochondrial DNA in the development of diabetic retinopathy," Investigative Ophthalmology \& Visual Science, vol. 56, no. 9, pp. 5133-5142, 2015.

[9] H. R. Pelzel, C. L. Schlamp, M. Waclawski, M. K. Shaw, and R. W. Nickells, "Silencing of Fem1cR3 gene expression in the DBA/2J mouse precedes retinal ganglion cell death and is associated with histone deacetylase activity," Investigative Ophthalmology \& Visual Science, vol. 53, no. 3, pp. 14281435, 2012.

[10] Q. Zhong and R. A. Kowluru, "Epigenetic changes in mitochondrial superoxide dismutase in the retina and the development of diabetic retinopathy," Diabetes, vol. 60, no. 4, pp. 1304-1313, 2011.

[11] Q. Zhong and R. A. Kowluru, "Epigenetic modification of Sod2 in the development of diabetic retinopathy and in the metabolic memory: role of histone methylation," Investigative Ophthalmology \& Visual Science, vol. 54, no. 1, pp. 244-250, 2013.

[12] G. Auclair and M. Weber, "Mechanisms of DNA methylation and demethylation in mammals," Biochimie, vol. 94, no. 11, pp. 2202-11, 2012.

[13] M. Barchitta, A. Quattrocchi, A. Maugeri, M. Vinciguerra, and A. Agodi, "LINE-1 hypomethylation in blood and tissue samples as an epigenetic marker for cancer risk: a systematic review and meta-analysis," PLoS One, vol. 9, no. 10, article e109478, 2014.

[14] P. E. Carreira, S. R. Richardson, and G. J. Faulkner, "L1 retrotransposons, cancer stem cells and oncogenesis," The FEBS Journal, vol. 281, no. 1, pp. 63-73, 2014.

[15] S. Fabris, D. Ronchetti, L. Agnelli et al., "Transcriptional features of multiple myeloma patients with chromosome 1q gain," Leukemia, vol. 21, no. 5, pp. 1113-1116, 2007.

[16] N. Rodić and K. H. Burns, "Long interspersed element-1 (LINE-1): passenger or driver in human neoplasms?," PLoS Genetics, vol. 9, no. 3, article e1003402, 2013.

[17] A. Amalraj, A. Pius, S. Gopi, and S. Gopi, "Biological activities of curcuminoids, other biomolecules from turmeric and their derivatives - a review," Journal of Traditional and Complementary Medicine, vol. 7, no. 2, pp. 205-233, 2017.

[18] D. Akbik, M. Ghadiri, W. Chrzanowski, and R. Rohanizadeh, "Curcumin as a wound healing agent," Life Sciences, vol. 116, no. 1, pp. 1-7, 2014.

[19] Y. Zhang, S. A. McClain, H.-M. Lee et al., "A novel chemically modified curcumin "normalizes" wound-healing in rats with experimentally induced type I diabetes: initial studies," Journal of Diabetes Research, vol. 2016, Article ID 5782904, 11 pages, 2016.

[20] J. Epstein, I. R. Sanderson, and T. T. Macdonald, "Curcumin as a therapeutic agent: the evidence from in vitro, animal and human studies," The British Journal of Nutrition, vol. 103, no. 11, pp. 1545-1557, 2010.

[21] T. Osawa and Y. Kato, "Protective role of antioxidative food factors in oxidative stress caused by hyperglycemia," Annals of the New York Academy of Sciences, vol. 1043, no. 1, pp. 440-451, 2005.

[22] J. M. Woo, D. Y. Shin, S. J. Lee et al., "Curcumin protects retinal pigment epithelial cells against oxidative stress via induction of heme oxygenase-1 expression and reduction of reactive oxygen," Molecular Vision, vol. 18, pp. 901-908, 2012.

[23] R. A. Kowluru and M. Kanwar, "Effects of curcumin on retinal oxidative stress and inflammation in diabetes," Nutrition \& Metabolism, vol. 4, no. 1, p. 8, 2007.

[24] W. M. Freeman, G. V. Bixler, R. M. Brucklacher et al., "Transcriptomic comparison of the retina in two mouse models of diabetes," Journal of Ocular Biology, Diseases, and Informatics, vol. 2, no. 4, pp. 202-213, 2009.

[25] P. Bogdanov, L. Corraliza, J. A. Villena et al., "The db/db mouse: a useful model for the study of diabetic retinal neurodegeneration," PLoS One, vol. 9, no. 5, article e97302, 2014.

[26] H. Candiloros, S. Muller, N. Zeghari, M. Donner, P. Drouin, and O. Ziegler, "Decreased erythrocyte membrane fluidity in poorly controlled IDDM. Influence of ketone bodies," Diabetes Care, vol. 18, no. 4, pp. 549-551, 1995.

[27] Y. H. Chen, H. C. Chou, S. T. Lin, Y. W. Chen, Y. W. Lo, and H. L. Chan, "Effect of high glucose on secreted proteome in cultured retinal pigmented epithelium cells: its possible 
relevance to clinical diabetic retinopathy," Journal of Proteomics, vol. 77, pp. 111-128, 2012.

[28] X. Jouven, R. N. Lemaître, T. D. Rea, N. Sotoodehnia, J. P. Empana, and D. S. Siscovick, "Diabetes, glucose level, and risk of sudden cardiac death," European Heart Journal, vol. 26, no. 20, pp. 2142-2147, 2005.

[29] A. Agodi, M. Barchitta, A. Quattrocchi et al., "Low fruit consumption and folate deficiency are associated with LINE-1 hypomethylation in women of a cancer-free population," Genes \& Nutrition, vol. 10, no. 5, p. 480, 2015.

[30] M. Barchitta, A. Quattrocchi, A. Maugeri et al., "LINE-1 hypermethylation in white blood cell DNA is associated with high-grade cervical intraepithelial neoplasia," BMC Cancer, vol. 17, no. 1, p. 601, 2017.

[31] M. Khullar, B. S. Cheema, and S. K. Raut, "Emerging evidence of epigenetic modifications in vascular complication of diabetes," Frontiers in Endocrinology, vol. 8, 2017.

[32] E. R. Gilbert and D. Liu, "Epigenetics: the missing link to understanding $\beta$-cell dysfunction in the pathogenesis of type 2 diabetes," Epigenetics, vol. 7, no. 8, pp. 841-852, 2012.

[33] C. Ling and L. Groop, "Epigenetics: a molecular link between environmental factors and type 2 diabetes," Diabetes, vol. 58, no. 12, pp. 2718-2725, 2009.

[34] J. Zheng, J. Cheng, Q. Zhang, and X. Xiao, "Novel insights into DNA methylation and its critical implications in diabetic vascular complications," Bioscience Reports, vol. 37, no. 2, p. BSR20160611, 2017.

[35] A. El-Osta, D. Brasacchio, D. Yao et al., "Transient high glucose causes persistent epigenetic changes and altered gene expression during subsequent normoglycemia," The Journal of Experimental Medicine, vol. 205, no. 10, pp. 2409-2417, 2008.

[36] M. Movassagh, M.-K. Choy, M. Goddard, M. R. Bennett, T. A. Down, and R. S.-Y. Foo, "Differential DNA methylation correlates with differential expression of angiogenic factors in human heart failure," PLoS One, vol. 5, no. 1, article e8564, 2010.

[37] H. Mönkemann, A. S. De Vriese, H. J. Blom et al., "Early molecular events in the development of the diabetic cardiomyopathy," Amino Acids, vol. 23, no. 1-3, pp. 331-336, 2002.

[38] L. Pirola, A. Balcerczyk, R. W. Tothill et al., "Genome-wide analysis distinguishes hyperglycemia regulated epigenetic signatures of primary vascular cells," Genome Research, vol. 21, no. 10, pp. 1601-1615, 2011.

[39] Z. Z. Liu, X. Z. Zhao, X. S. Zhang, and M. Zhang, "Promoter DNA demethylation of Keap1 gene in diabetic cardiomyopathy," International Journal of Clinical and Experimental Pathology, vol. 7, no. 12, pp. 8756-8762, 2014.

[40] J. Zhong, G. Agha, and A. A. Baccarelli, "The role of DNA methylation in cardiovascular risk and disease: methodological aspects, study design, and data analysis for epidemiological studies," Circulation Research, vol. 118, no. 1, pp. 119-131, 2016.

[41] C. G. Bell, A. E. Teschendorff, V. K. Rakyan, A. P. Maxwell, S. Beck, and D. A. Savage, "Genome-wide DNA methylation analysis for diabetic nephropathy in type 1 diabetes mellitus," BMC Medical Genomics, vol. 3, no. 1, article 33, 2010.

[42] R. Peng, H. Liu, H. Peng et al., "Promoter hypermethylation of let-7a-3 is relevant to Its down-expression in diabetic nephropathy by targeting UHRF1," Gene, vol. 570, no. 1, pp. 57-63, 2015.
[43] C. Sapienza, J. Lee, J. Powell et al., "DNA methylation profiling identifies epigenetic differences between diabetes patients with ESRD and diabetes patients without nephropathy," Epigenetics, vol. 6, no. 1, pp. 20-28, 2011.

[44] E. Agardh, A. Lundstig, A. Perfilyev et al., "Genome-wide analysis of DNA methylation in subjects with type 1 diabetes identifies epigenetic modifications associated with proliferative diabetic retinopathy," BMC Medicine, vol. 13, no. 1, article $182,2015$.

[45] R. A. Kowluru and Y. Shan, "Role of oxidative stress in epigenetic modification of MMP-9 promoter in the development of diabetic retinopathy," Graefe's Archive for Clinical and Experimental Ophthalmology, vol. 255, no. 5, pp. 955962, 2017.

[46] J. Wang, T. Takeuchi, S. Tanaka et al., "A mutation in the insulin 2 gene induces diabetes with severe pancreatic beta-cell dysfunction in the Mody mouse," The Journal of Clinical Investigation, vol. 103, no. 1, pp. 27-37, 1999.

[47] E. G. Hong, D. Y. Jung, H. J. Ko et al., "Nonobese, insulindeficient Ins2Akita mice develop type 2 diabetes phenotypes including insulin resistance and cardiac remodeling," American Journal of Physiology Endocrinology and Metabolism, vol. 293, no. 6, pp. E1687-E1696, 2007.

[48] R. A. Kowluru, A. Kowluru, M. Mishra, and B. Kumar, "Oxidative stress and epigenetic modifications in the pathogenesis of diabetic retinopathy," Progress in Retinal and Eye Research, vol. 48, pp. 40-61, 2015.

[49] S. Tewari, Q. Zhong, J. M. Santos, and R. A. Kowluru, "Mitochondria DNA replication and DNA methylation in the metabolic memory associated with continued progression of diabetic retinopathy," Investigative Ophthalmology \& Visual Science, vol. 53, no. 8, pp. 4881-4888, 2012.

[50] M. Mishra and R. A. Kowluru, "The role of DNA methylation in the metabolic memory phenomenon associated with the continued progression of diabetic retinopathy," Investigative Ophthalmology \& Visual Science, vol. 57, no. 13, pp. 57485757, 2016.

[51] A. S. Olsen, M. P. Sarras, A. Leontovich, and R. V. Intine, "Heritable transmission of diabetic metabolic memory in zebrafish correlates with DNA hypomethylation and aberrant gene expression," Diabetes, vol. 61, no. 2, pp. 485-491, 2012.

[52] I. Afanas'ev, "New nucleophilic mechanisms of ros-dependent epigenetic modifications: comparison of aging and cancer," Aging and Disease, vol. 5, no. 1, pp. 52-62, 2014.

[53] P. Tokarz, K. Kaarniranta, and J. Blasiak, "Inhibition of DNA methyltransferase or histone deacetylase protects retinal pigment epithelial cells from DNA damage induced by oxidative stress by the stimulation of antioxidant enzymes," European Journal of Pharmacology, vol. 776, pp. 167-175, 2016.

[54] V. Kant, A. Gopal, D. Kumar et al., "Curcumin-induced angiogenesis hastens wound healing in diabetic rats," The Journal of Surgical Research, vol. 193, no. 2, pp. 978-988, 2015.

[55] A. Shah and S. Amini-Nik, "The role of phytochemicals in the inflammatory phase of wound healing," International Journal of Molecular Sciences, vol. 18, no. 5, 2017.

[56] R. L. Thangapazham, S. Sharad, and R. K. Maheshwari, "Phytochemicals in wound healing," Advances in Wound Care, vol. 5, no. 5, pp. 230-241, 2016.

[57] Y. Abe, S. Hashimoto, and T. Horie, "Curcumin inhibition of inflammatory cytokine production by human peripheral blood 
monocytes and alveolar macrophages," Pharmacological Research, vol. 39, no. 1, pp. 41-47, 1999.

[58] E. Balogun, M. Hoque, P. Gong et al., "Curcumin activates the haem oxygenase-1 gene via regulation of $\mathrm{Nrf2}$ and the antioxidant-responsive element," The Biochemical Journal, vol. 371, no. 3, pp. 887-895, 2003.

[59] M. T. Huang, T. Lysz, T. Ferraro, T. F. Abidi, J. D. Laskin, and A. H. Conney, "Inhibitory effects of curcumin on in vitro lipoxygenase and cyclooxygenase activities in mouse epidermis," Cancer Research, vol. 51, no. 3, pp. 813-819, 1991.

[60] A. C. Reddy and B. R. Lokesh, "Studies on spice principles as antioxidants in the inhibition of lipid peroxidation of rat liver microsomes," Molecular and Cellular Biochemistry, vol. 111, no. 1-2, pp. 117-124, 1992.

[61] G. Scapagnini, C. Colombrita, M. Amadio et al., "Curcumin activates defensive genes and protects neurons against oxidative stress," Antioxidants \& Redox Signaling, vol. 8, no. 3-4, pp. 395-403, 2006.

[62] S. Singh and B. B. Aggarwal, "Activation of transcription factor NF-kappa B is suppressed by curcumin (diferuloylmethane) [corrected]," The Journal of Biological Chemistry, vol. 270, no. 42, pp. 24995-25000, 1995.

[63] M. Susan and M. N. Rao, "Induction of glutathione Stransferase activity by curcumin in mice," Arzneimittel-Forschung, vol. 42, no. 7, pp. 962-964, 1992.

[64] J. H. Woo, Y. H. Kim, Y. J. Choi et al., "Molecular mechanisms of curcumin-induced cytotoxicity: induction of apoptosis through generation of reactive oxygen species, downregulation of $\mathrm{Bcl}-\mathrm{XL}$ and $\mathrm{IAP}$, the release of cytochrome $\mathrm{c}$ and inhibition of Akt," Carcinogenesis, vol. 24, no. 7, pp. 1199-1208, 2003.

[65] J. C. Howell, E. Chun, A. N. Farrell et al., "Global microRNA expression profiling: curcumin (diferuloylmethane) alters oxidative stress-responsive microRNAs in human ARPE-19 cells," Molecular Vision, vol. 19, pp. 544-560, 2013.

[66] V. Pittalà, A. Fidilio, F. Lazzara et al., "Effects of novel nitric oxide-releasing molecules against oxidative stress on retinal pigmented epithelial cells," Oxidative Medicine and Cellular Longevity, vol. 2017, Article ID 1420892, 11 pages, 2017.

[67] R. A. Sharma, S. A. Euden, S. L. Platton et al., "Phase I clinical trial of oral curcumin: biomarkers of systemic activity and compliance," Clinical Cancer Research, vol. 10, no. 20, pp. 6847-6854, 2004.

[68] V. Ravindranath and N. Chandrasekhara, "Absorption and tissue distribution of curcumin in rats," Toxicology, vol. 16, no. 3, pp. 259-265, 1980.

[69] V. Ravindranath and N. Chandrasekhara, "Metabolism of curcumin-studies with [3H] curcumin," Toxicology, vol. 22, no. 4, pp. 337-344, 1981.

[70] M. N. A. Mandal, J. M. R. Patlolla, L. Zheng et al., "Curcumin protects retinal cells from light-and oxidant stress-induced cell death," Free Radical Biology \& Medicine, vol. 46, no. 5, pp. 672-679, 2009.

[71] P. Suryanarayana, M. Saraswat, T. Mrudula, T. P. Krishna, K. Krishnaswamy, and G. B. Reddy, "Curcumin and turmeric delay streptozotocin-induced diabetic cataract in rats," Investigative Ophthalmology \& Visual Science, vol. 46, no. 6, p. 2092, 2005. 


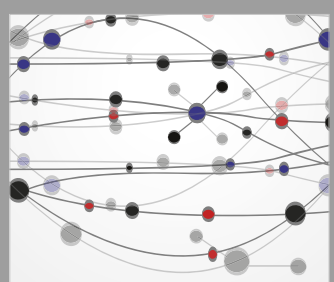

The Scientific World Journal
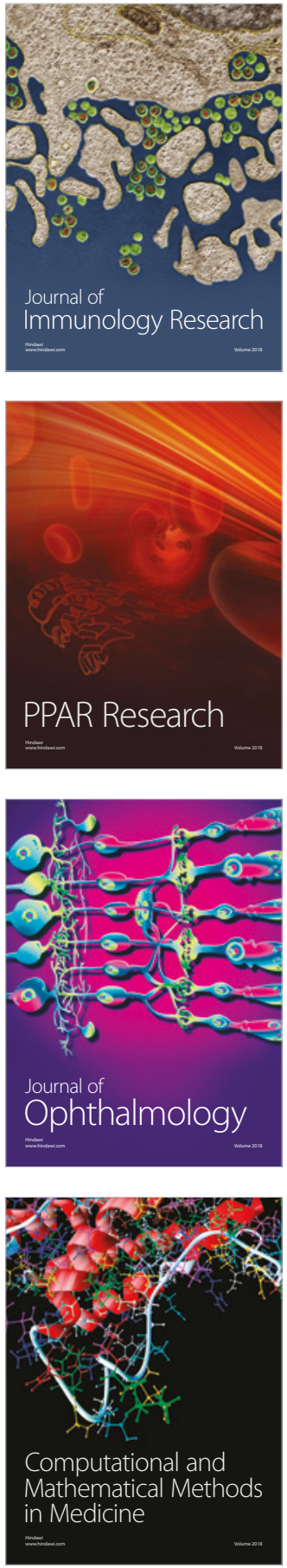

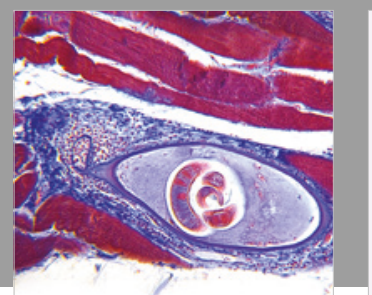

Gastroenterology Research and Practice

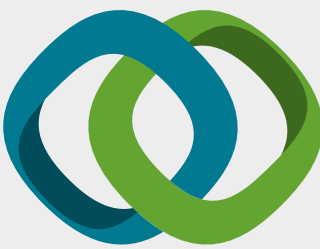

\section{Hindawi}

Submit your manuscripts at

www.hindawi.com
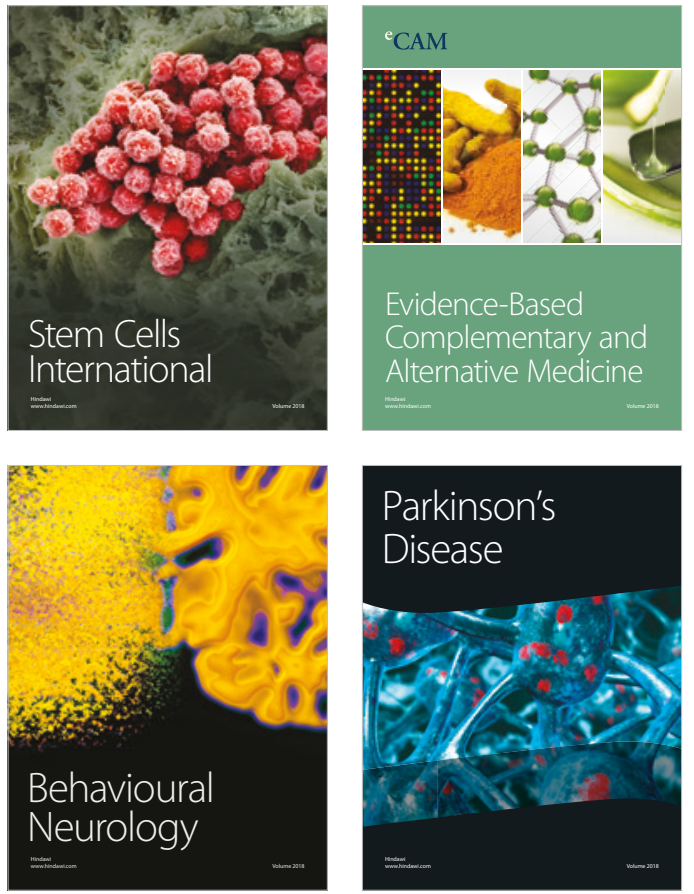

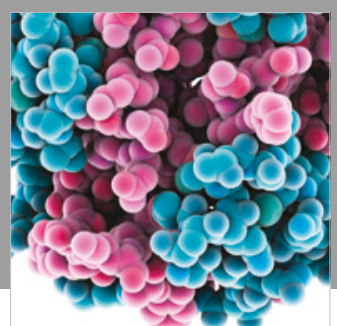

ournal of

Diabetes Research

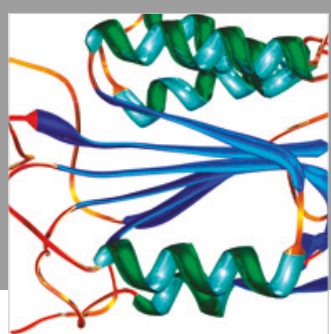

Disease Markers
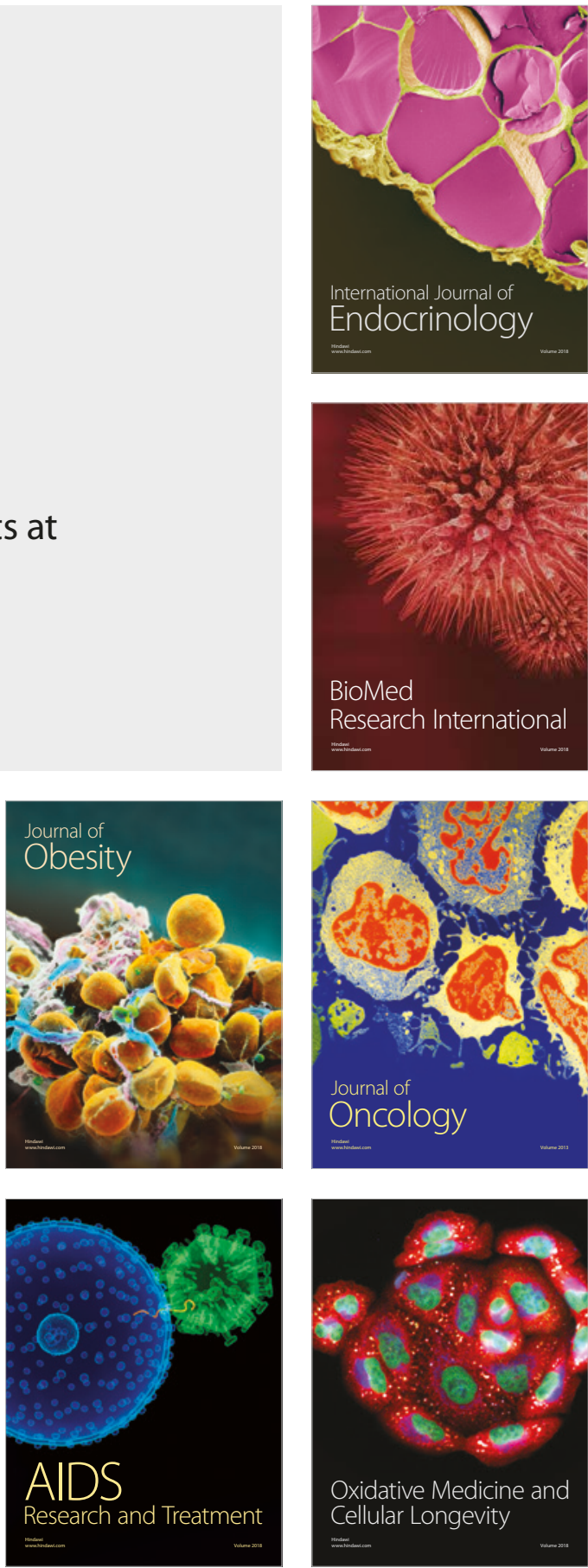